\title{
THE MEMBERSHIP VOTES
}

\section{The Current Elections Will Shape The MRS's Future}

As we move into the fall of 1984 , the activities of the Materials Research Society are dominated by detailed planning for the 1984 Fall Meeting in Boston, the advance preparations for the 1985 Spring Meeting in San Francisco, membership drives for both student and regular members, preparations for the MRS to publish the conference Proceedings series, and other activities which will contribute to the Society's growth and prosperity in future years. This is the time also for members of the Society to elect the officers and councilors who will lead the Society in 1985. These elections are extremely important to the Society because we have a large number of positions to be filled and the results will shape the future of the MRS for years to come. In 1984 we have been fortunate to have a very capable and dedicated group of individuals to serve as officers of the Society. I would like briefly to take note of some of their contributions, which demonstrate the great demands MRS service imposes.

\section{The MRS's Officers in 1984}

Elton Kaufmann has provided monumental services to the Society, and assistance to me, during 1984 as First Vice President. He has been asked to take responsibility for some of the most difficult and demanding problems facing the MRS, and he has resolved them in an exemplary manner. Among other things, he has provided guidance to the Program Committee, the Corporate Participation Committee, and the Publicity and Public Relations Working Group as they have launched many new initiatives on behalf of the Society. As provided in our Constitution, the First Vice President is also our President Elect, and the Society is very fortunate that Elton will become our President in 1985.

Bill Appleton, our Second Vice President, has provided direction, inspiration and guidance as the officer with oversight responsibility for the Publications and Education committees. Both have undertaken major initiatives under his guidance, which will benefit the Society for years to come. Bill also has organized a superb Plenary Session for our upcoming Annual Meeting that will be of interest to all materials professionals. I regret to inform you that Bill's other professional and institutional commitments will not permit him to seek a higher office in the Society at this time. The MRS will miss his leadership in 1985 but it will profit for years to come from his efforts in 1984 .

Kathy Taylor will conclude her term as Treasurer in 1984. Kathy has been our Treasurer for as long as anyone can remember. She has guided the Society's finances during some very difficult times, and her stewardship has resulted in the development and administration of a financial apparatus that has permitted us to operate economically and efficiently, and on a sound accounting basis. The MRS is

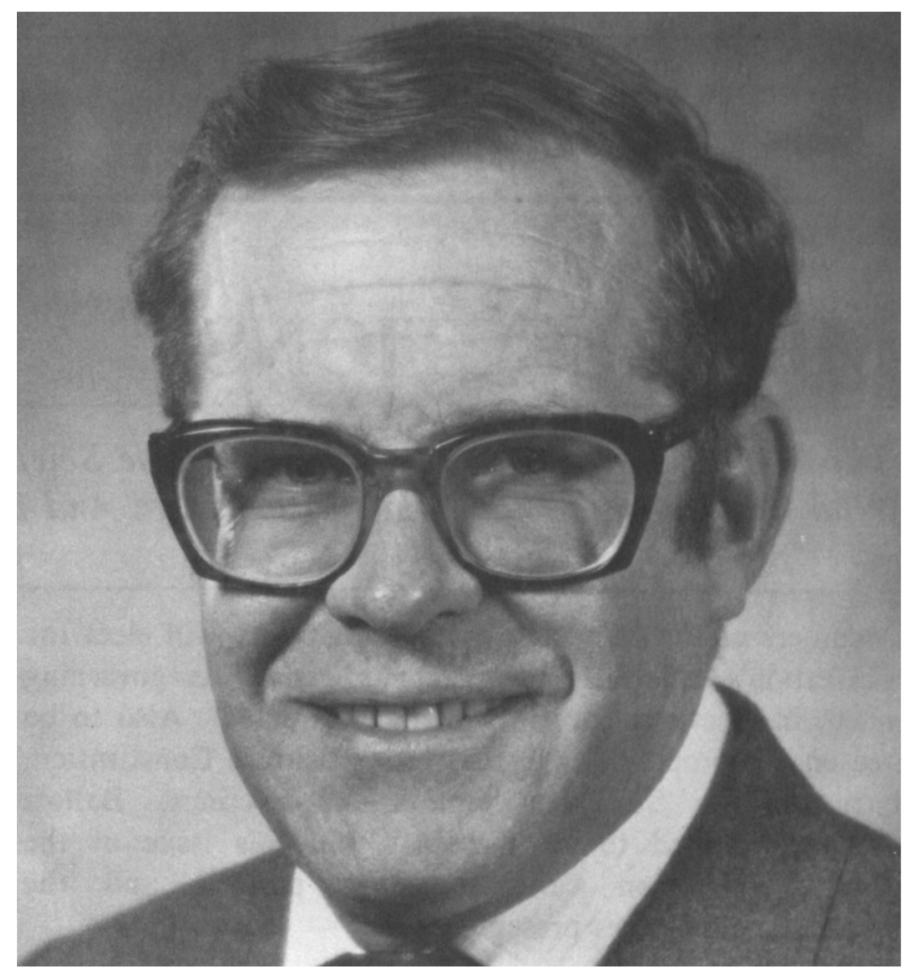

"WOODY" WHITE

grateful for the leadership she has provided.

Dick Schwoebel also concludes his term in 1984 as Secretary of the Society and Chairman of the Membership Committee. He has served in these positions for the last four years. Dick was largely responsible for drafting the current Constitution and Bylaws of the Society, and he is overseeing the preparation of revisions to the Constitution, which will be presented to the membership for ratification in the near future. He has spent uncounted hours on behalf of the MRS and his efforts have contributed greatly to our growth and prosperity.

Each of these individuals has made significant contributions to the Materials Research Society, and their work together as a team has made possible the explosive growth of our membership and services in recent months. Those who have chosen because of their other professional commitments not to seek office in 1985 will be greatly missed. Fortunately, all will remain active on MRS committees, where their experience can be well utilized.

\section{Candidates for Officer and Councilor}

The Society is fortunate that an outstanding group of candidates have come forward to help lead the MRS in 1985. The Nominating Committee, under the leadership of Past President Harry Leamy, has prepared an excellent slate of candidates to contest for vacant positions. As provided in 
our Constitution, Elton becomes President next year, having served in 1984 as First Vice President and President Elect. Positions that must be filled are First Vice President, Second Vice President, Secretary, and Treasurer. The Vice Presidents serve for one year, and the Secretary and Treasurer for two. Candidates put forward by the Nominating Committee are profiled in this issue of the Bulletin. Each has served the Society well in other capacities. Their level of commitment in these positions must be great, and their challenges will not be easy, but each has demonstrated through past action the dedication and ability necessary to provide leadership for the Society.

The Nominating Committee has also prepared an excellent slate of candidates for the five positions that will become vacant on the Society's Council in 1985. The Council is the Society's governing body, and the decisions it makes determine the Society's future growth and direction. Each candidate has served the Society previously in some capacity. As the terms of Councilors run for three years, the votes cast in this election will influence the Society for years to come.

You will receive a ballot and other election materials from the Society shortly. Your vote is one of your most important privileges and responsibilities as an MRS member. I urge you to participate in this process, which will shape the future of the Materials Research Society.

\section{Changes to the Constitution}

The Society's Constitution was drafted several years ago. Since then the MRS has undergone enormous growth in membership, and substantial changes in activities and composition. As a result, several changes to the Constitution must be made for it to be consistent with our present structure. The Membership Committee, under the direction of Dick Schwoebel, has drafted proposed changes to the Constitution in order to accomplish this goal. Ed Beauchamp has made major contributions to this effort. These changes will be submitted to you, our members, for ratification. When you receive this information please consider it carefully and register your vote promptly.

\section{Our Annual Fall Meeting}

The Fall Meeting in Boston Nov. 26-30 promises to be the largest and best in the history of the Materials Research Society. More than 950 presentations will be made in the 16 topical symposia that comprise the technical program. Attendance is expected to be approximately 2,000 scientists and engineers. For the first time at an MRS meeting, a major Equipment Show will be included, and a formal job placement service will be provided. An expanded schedule of nine short courses will be offered. Articles describing the meeting and show will appear in the October issue of Physics Today and Semiconductor International, and other articles will appear in forthcoming issues of several other trade journals. Dozens of people have made major contributions to the planning of this meeting. If you haven't already, make plans now to attend-and participate in-the Boston meeting. It is the premier meeting in the world for materials professionals.

I hope to see you there.

\section{C.W. "WOODY" WHITE President}

\section{HYDROTHERMAL REACTIONS}

\section{MRS-Sponsored Second International Symposium \\ Set To Be Held In August, 1985, At Penn State}

The Second International Symposium on Hydrothermal Reactions will be held Aug. 12-14, 1985, at The Pennsylvania State University, University Park, Pennsylvania. Growing out of meetings in Sweden and Japan, the conference is intended to bring together scientists active in research on high pressure aqueous and related chemical systems. Included will be applications to hydrothermal geochemistry, reactions used to prepare electronic materials and ceramics, hydrothermal crystal growth, near- and supercritical separations, corrosion chemistry, and the physical chemistry of fluids at high pressures and temperatures. It is sponsored by the Materials Research Society and other organizations.

\section{Nobel Symposium}

During the Nobel Symposium on "The Chemistry and Geochemistry of Solutions at High Temperatures and Pressures" in Sweden in 1979, participants became keenly aware that periodic meetings among chemists, geochemists, materials scientists, and others actively investigating hydrothermal systems could substantially enhance the rapid sharing of information among researchers. The symposium concluded with a discussion of means by which such interaction would be possible (see p. 541, Nobel Symposium Proceedings, Physics and Chemistry of the Earth, volumes 13 and 14, edited by D.T. Richard and F.E. Wickman).

In response, Professor Shigeyuki Somiya of the Tokyo Institute of Technology and his associates organized the First International Symposium on Hydrothermal Reactions in Yokohama in 1982 (Proceedings volume distributed by Gakujutsu Bunken Fukyu-kai, Tokyo Institute of Technology, Ookayama, Meguro, Tokyo 152, Japan). This meeting was attended by 167 participants, and at its conclusion it was proposed that the series be continued triennially. The site of the Second International Symposium was designated to be The Pennsylvania State University.

\section{[Continued on Page 12]}

